\title{
Effect of Maternal Obesity on Labor Induction in Postdate Pregnancies
}

\author{
Farid I. Hassan, Mofeed F. Mohamed, Salah Eldin M. Ali
}

Obstetrics and Gynecology Department,Faculty of Medicine,Al -Azhar University

Corresponding author: Salah Eldin M. Ali; Mobile: 01111194669; Email: salah.khatab.2020@ gmail.com

\begin{abstract}
Background: Obesity has been recognized by WHO as "a pandemic nutritional disorder which represents a rapidly growing threat to the health of populations of countries world wide". As obesity increases, so does the number of women of reproductive age who are overweight and obese. The problems related to the management of obesity in pregnancy are many. There are both short-and long-term complications and implications for both mother and fetus.

Aim of the Work: Evaluation of the effect of maternal obesity on labor induction in post-date pregnancies. Patients and Methods: This prospective case-control study was conducted on two hundred (200) pregnant women who were divided into 2 groups: 100 non-obese pregnant women with BMI $<30 \mathrm{~kg} / \mathrm{m}^{2}$ and 100 obese pregnant women with BMI $\geq 30 \mathrm{~kg} / \mathrm{m}^{2}$. These women were investigated for success of induction of labor. All women participants were recruited from Al Hussein and Military Hospitals Departments in the period from $12-2017$ till $11-2018$.

Results: As regards success of induction, our study revealed that a greater number of obese women had failed induction ending in CS delivery ( no dilatation of cervix after 24 hours of vaginal prostaglandin ) compared to their normal weight counterparts.

Conclusion: Obesity is associated with increased incidence of failure of induction of labor ending in CS delivery, increased duration of induction of labor till vaginal deliveries, low Apgar score and increased fetal birth weight.
\end{abstract}

Keywords: maternal obesity, labor induction, post-date pregnancies.

\section{INTRODUCTION}

Obesity represents a state of excess body fat. Normal, healthy men have a body fat percentage of $15-20 \%$, while normal, healthy women have a percentage of approximately $25-$ $30 \%{ }^{(1)}$. Although body weight is easily obtained, it is a limited index of obesity because the differences in weight among individuals are only partly the result of variations in body fat ${ }^{(2)}$.

The body mass index (BMI), also known as the quetelet index, is used more commonly than body fat percentage to define obesity. In general, BMI correlates closely with the degree of body fat in most settings; however, this correlation is weaker at low BMIs ${ }^{(3)}$. An individual's BMI is calculated as weight $(\mathrm{kg}) /$ height $\left(\right.$ meter $\left.^{2}\right)$.

Although several classifications and definitions for degrees of obesity are accepted, the most widely accepted classifications are those from the $\boldsymbol{W H O}{ }^{(4)}$, based on BMI. The WHO designations included the following:

- Grade 1 overweight (commonly called overweight): BMI of $25-29.9 \mathrm{~kg} / \mathrm{m}^{2}$.

- Grade 2 overweight (commonly called obesity): BMI of 30-39.9 kg/m².

- Grade 3 overweight (commonly called severe or morbid obesity): BMI greater than or equal to $40 \mathrm{~kg} / \mathrm{m}^{2}$.

Obesity became a worldwide epidemic. Worldwide obesity has more than doubled since 1980. In 2014, more than 1.9 billion adults, 18 years and older, were overweight. Of these over
600 million were obese. These metabolic disorders are dramatically increasing among adults in the Eastern Mediterranean Region. Data for adults aged 15 years and older from 16 countries in the Region showed the highest levels of overweight and obesity in Egypt, Bahrain, Jordan, Kuwait, Saudi Arabia and United Arab Emirates. The prevalence of overweight and obesity in these countries ranges from $74 \%$ to $86 \%$ in women and $69 \%$ to $77 \%$ in men ${ }^{(4)}$.

As obesity increases, so does the number of women of reproductive age who are overweight and obese. Obese women have reproductive disadvantages. This translates into difficulty in achieving pregnancy, early and recurrent pregnancy loss, preterm delivery, and a myriad of increased obstetrical, medical and surgical complications with pregnancy, labor, delivery, and the puerperium ${ }^{(5)}$. Obesity in pregnancy has shown to be associated with significantly increased risk of post-term pregnancy ${ }^{(2)}$. Lateterm and post-term pregnancies are associated with an increased risk of perinatal morbidity and mortality ${ }^{(6)}$. Women with high body mass index (BMI) and prolonged pregnancy had an increasingly prevalent clinical problem ${ }^{(2)}$.

Management of prolonged pregnancies in obese women, however, is difficult because IOL is associated with a high risk of caesarean section and its attendant complications of infection, haemorrhage and thrombosis whereas conservative management is associated with an 
increased risk of perinatal mortality. The clinician managing an obese woman with a prolonged pregnancy therefore faces the dilemma of whether to; induce her and risk caesarean section delivery and its complications, which can include maternal death, to book an elective caesarean section and thereby reduce the increased risks associated with emergency caesarean section, or to wait so as to maximise the chance of spontaneous labour, thereby reducing the risk of caesarean section but increasing the risk of fetal death, even with outpatient monitoring. There are few published data that inform the clinician and their patients as to the prevalence of complications with each of these options ${ }^{(3)}$.

Optimal control of obesity begins before conception. Weight loss before pregnancy, achieved by surgical or nonsurgical methods showed to be the most effective intervention to improve medical comorbidities. Obese women who have even small weight reductions before pregnancy may have improved pregnancy outcomes ${ }^{(5)}$.

Weight reduction is not advisable during pregnancy ${ }^{(6)}$. Recommended weight gain in obese women is 11 to 20 pounds, and several dietary interventions to limit weight gain to these targets have been reported. These include lifestyle interventions and physical activity ${ }^{(7)}$.

\section{AIM OF THE WORK}

The aim of this study was to evaluate the effect of maternal obesity on labor induction in post-date pregnancies.

\section{PATIENTS AND METHODS Study setting:}

This study was carried out at Al Hussein and Military Hospitals Departments in the period from $12-2017$ till $11-2018$.

The study was approved by the Ethics Board of Al-Azhar University.

\section{Type of the study:}

A prospective case-control study in 100 women with BMI $\geq 30 \mathrm{~kg} / \mathrm{m}^{2}$ and 100 women with BMI $<30 \mathrm{~kg} / \mathrm{m}^{2}$ and post-date $\geq 41 \mathrm{wks}$, not in labor admitted for induction of labor. These women were investigated for success of induction of labor.

\section{PATIENTS AND METHODS}

200 pregnant women were included in the study fulfilling the following inclusion and exclusion criteria:

\section{Inclusion criteria:}

1. Pregnant woman.

2. Post date $\geq 41$ weeks.

3. Woman not in labor

4. Patient acceptance to join the study after signing an informed consent.

\section{Exclusion criteria:}

\section{Women with Contraindications of induction of} labor.

○ Malpresentation.

- Cephalopelvic disproportion.

- Placenta previa and or vasa previa.

- Previous uterine scar.

○ Multiple gestation.

- Indications of emergency CS.

- Any patient who refused to be a part of

IUFD. the study.

They were divided into 2 groups based on their body mass index (BMI):-

Group (A): included the pregnant women with a BMI $<30 \mathrm{~kg} / \mathrm{m}^{2}$ (non-obese)

Group (B): included the pregnant women with a BMI $\geq 30 \mathrm{~kg} / \mathrm{m}^{2}$ (obese).

- A woman is classified as obese if BMI $\geq$ $30 \mathrm{~kg} / \mathrm{m}^{2}$.

- Prolonged pregnancy was defined as delivery on or after (41+ 0 weeks) of gestation.

- Patients' ages ranged from 18-36 years, with a mean of $26.81 \pm 5.4$ years. GA ranged from 287-294 days with mean of $290.34 \pm 2.27$ days

The study included 105 nulliparous (55 obese and 50 non-obese) and 95 Multiparous (45 obese and 50 non-obese) women. The BMI of the non-obese group ranged from $26-28 \mathrm{~kg} / \mathrm{m}^{2}$ with a mean of $26.97 \pm 0.8 \mathrm{~kg} / \mathrm{m}^{2}$, while the BMI of the obese group ranged from $30-39 \mathrm{~kg} / \mathrm{m}^{2}$ with a mean of $34.28 \pm 2.87 \mathrm{~kg} / \mathrm{m}^{2}$.

The Bishop score ${ }^{(8)}$ of the non-obese group ranged from $0-4$ with mean of $2.16 \pm 1.48$, while the bishop score of the obese group ranged from $0-6$ with mean of $3.04 \pm 1.53$.

The following was done for the women included in this study:

- $\quad$ First informed consent was obtained.

- Determination of gestational age by calculation of first day of last menstrual period or from 1st trimesteric U/S scan or by US estimated gestational age at presentation.

- Proper history taking, general and abdominal examinations was done to determine age, parity and to exclude any medical or surgical risk then digital 
examination was performed to determine Bishop score.

- The Bishop score is defined based on scoring cervical position, cervical consistency, fetal station, cervical effacement and cervical dilatation ${ }^{(\mathbf{8})}$.

Obstetric U/S scan was done to assess fetal biometry, fetal heart activity, presentation, localization and grading of the placenta, amount of amniotic fluid and to exclude multifetal pregnancy.

Patients with an unfavorable cervix were defined as patients with Bishop Score $\leq 6$. Cervical ripening was done for these patients with vaginal misoprostol as follows:

25 microgram every 6 hours in the posterior fornix of the vagina followed by full reassessment 6 hours after initial does unless clinical condition indicates earlier assessment. Maximal allowable dose is 100 microgram. For all women undergoing labor induction, external fetal monitoring was done. Successful induction is defined as vaginal delivery.

\section{Outcome measures:}

- Delivery outcomes including; mode of delivery, indications of CS (if CS was done), duration of induction of labor till delivery, incidence of postpartum haemorrhage and perineal tear.

- Neonatal outcomes including: fetal birth weight, Apgar score at 5 minutes.

\section{RESULTS}

This prospective study was conducted for 200 pregnant women (100 obese and 100 nonobese) who are post-date ( $\geq 41 \mathrm{wks})$ and not in labor. Patients having contraindication for induction of labor were excluded e.g.: malpresentation, cephalopelvic disproportion, placenta previa, previous uterine scar, multiple gestations, indications for emergency CS. Patients were recruited from the Gynecology and Obstetrics Casualty Departments at Al Hussein and Military Hospitals, during the period from 12 -2017 till $11-2018$.

Our goal was to assess the effect of obesity on success of induction of labour in prolonged pregnancy.

Therefore the aim of this research was to investigate the progression of labor in normal weight and obese pregnant women in order to reach practical recommendations regarding perinatal care and labor management in this obstetrically high risk population.

Table (1): Comparison between obese and nonobese of different studied groups in relation to percentage of vaginal deliveries.

\begin{tabular}{|c|c|c|c|}
\hline Variable & $\begin{array}{c}\text { Obese (n } \\
\text { = 100) }\end{array}$ & $\begin{array}{c}\text { Non-obese } \\
(\mathbf{n}=\mathbf{1 0 0})\end{array}$ & $\begin{array}{c}\text { P } \\
\text { value }\end{array}$ \\
\hline $\begin{array}{c}\text { Percentage of } \\
\text { vaginal } \\
\text { deliveries \% }\end{array}$ & $\mathbf{7 1}$ & $\mathbf{7 8}$ & $\mathbf{0 . 1 6 5}$ \\
\hline \multicolumn{2}{|c|}{ On }
\end{tabular}

On comparing between 100 obese and 100 non obese women in relation to percentage of vaginal deliveries, we found slight increase in the percentage of vaginal deliveries in the non-obese group compared to obese group but not statistically significant $(\mathrm{P}$ value $>0.05)$.

Table (2): Comparison between obese and nonobese of different studied groups in relation to percentage of cesarean sections.

\begin{tabular}{|c|c|c|c|}
\hline Variable & $\begin{array}{c}\text { Obese }(\mathbf{n} \\
\mathbf{1 0 0})\end{array}$ & $\begin{array}{c}\text { Non-obese } \\
(\mathbf{n = 1 0 0})\end{array}$ & $\begin{array}{c}\text { P } \\
\text { value }\end{array}$ \\
\hline $\begin{array}{c}\text { Percentage } \\
\text { of Cesarean } \\
\text { sections \% }\end{array}$ & $\mathbf{2 9}$ & $\mathbf{2 2}$ & $\mathbf{0 . 1 6 5}$ \\
\hline
\end{tabular}

On comparing between 100 obese and 100 non obese women in relation to percentage of cesarean sections, we found slight increase in the percentage of cesarean sections in the obese group compared to the non-obese group but not statistically significant $(\mathrm{P}$ value $>0.05)$.

Table (3): Comparison between obese and non-obese of different studied groups regarding the percentage of different indications for CS.

\begin{tabular}{|l|c|c|c|c|c|}
\hline \multirow{2}{*}{ Different indications for CS } & \multicolumn{2}{|c|}{ Obese } & \multicolumn{2}{|c|}{ Non-obese } & \multirow{2}{*}{ P value } \\
\cline { 2 - 5 } & No. & Percentage & No. & percentage & \\
\cline { 1 - 4 } Failed induction & 6 & $21 \%$ & 7 & $32 \%$ & \multirow{2}{*}{0.3} \\
\hline Fetal distress & 9 & $31 \%$ & 9 & $41 \%$ & \\
\cline { 1 - 4 } Arrest of progress & 14 & $48 \%$ & 6 & $27 \%$ & \\
\hline Total CS & 29 & $100 \%$ & 22 & $100 \%$ & \\
\hline
\end{tabular}

On comparing between obese and non-obese women regarding the percentage of different indications for $\mathrm{CS}$, we found no statistically significant difference between the 2 groups ( $\mathrm{P}$ value $>0.05$ ). 
Table (4): Comparison between obese and non-obese of different studied groups in relation to no. of doses of vagiprost needed for successful induction of labor.

\begin{tabular}{|c|c|c|c|c|c|}
\hline \multirow{2}{*}{$\begin{array}{l}\text { No. of Vagiprost doses needed for } \\
\text { successful induction of labor }\end{array}$} & \multicolumn{2}{|c|}{ Obese } & \multicolumn{2}{|c|}{ Non-obese } & \multirow[b]{2}{*}{$P$ value } \\
\hline & No. & Percentage & No. & Percentage & \\
\hline 1 dose & 26 & $36 \%$ & 30 & $39 \%$ & \multirow{5}{*}{0.952} \\
\hline 2 doses & 18 & $26 \%$ & 20 & $26 \%$ & \\
\hline 3 doses & 16 & $22 \%$ & 15 & $19 \%$ & \\
\hline 4 doses & 11 & $16 \%$ & 13 & $16 \%$ & \\
\hline Total successful induction of labor & 71 & $100 \%$ & 78 & $100 \%$ & \\
\hline
\end{tabular}

On comparing between obese and non-obese women in relation to percentage of successful inductions of labor with no. of doses of vagiprost needed for successful induction of labor, we found slight increase in the no. of doses needed for VD in the obese group compared to non-obese group but not statistically significant ( $\mathrm{P}$ value $>0.05$ ).

Table (5): Comparison between obese and non-obese of different studied groups in relation to duration of IOL till vaginal delivery

\begin{tabular}{|c|c|c|c|}
\hline Variable & $\begin{array}{c}\text { Obese } \\
\text { Mean } \pm \text { 1 Std. Deviation }\end{array}$ & $\begin{array}{c}\text { Non-obese } \\
\text { Mean } \pm \text { 1 Std. Deviation }\end{array}$ & P value \\
\hline $\begin{array}{c}\text { Duration of induction of labor } \\
\text { (hrs.) }\end{array}$ & $26.19 \pm 7.561$ & $23.61 \pm 7.392$ & 0.037 \\
\hline
\end{tabular}

On comparing between obese and non-obese women in relation to duration for induction of labor till vaginal delivery, we found slight increase in the duration for induction of labor till vaginal delivery in the obese group compared to non-obese group but not statistically significant $(\mathrm{P}$ value $>0.05)$.

Table (6): Comparison between nullipara and multipara of different studied groups in relation to no. of pastdate women in obese, non-obese and both

\begin{tabular}{|l|c|c|c|}
\hline & Nullipara & Multipara & P value \\
\cline { 1 - 3 } Obese (n= 100) & 55 & 45 & \multirow{2}{*}{0.285} \\
\cline { 1 - 3 } Non-obese (n= 100) & 50 & 50 & \\
\hline Total & 105 & 95 & \\
\hline
\end{tabular}

On comparing between 100 obese and 100 non-obese women who underwent induction of labor for postdate pregnancies in relation to parity, we found slight increase in the no. of past-date nulliparous women compared to multiparous women but not statistically significant $(\mathrm{P}$ value $>0.05)$.

Table (7): Comparison between obese and non-obese of different studied groups in relation to percentage of postpartum hemorrhage cases (estimated blood loss $>500 \mathrm{ml}$ for vaginal delivery and $>1000 \mathrm{ml}$ in CS delivery)

\begin{tabular}{|c|c|c|c|}
\hline Variable & $\begin{array}{c}\text { Obese } \\
(\mathbf{n}=\mathbf{1 0 0})\end{array}$ & Non-obese $(\mathbf{n}=\mathbf{1 0 0})$ & P value \\
\hline $\begin{array}{c}\text { Percentage postpartum hemorrhage } \\
\text { cases }\end{array}$ & 2 & 0 & 0.155 \\
\hline
\end{tabular}

On comparing between 100 obese and 100 non-obese women in relation to percentage of postpartum hemorrhage cases, we found only 2 cases of postpartum hemorrhage in the obese group compared to no cases in the non obese group. No statistical significance was found ( $\mathrm{P}$ value $>0.05$ ).

Table (8): Comparison between obese and non-obese of different studied groups in relation to percentage of cases with lacerations.

\begin{tabular}{|c|c|c|c|c|c|}
\hline \multirow{2}{*}{ Variable } & \multicolumn{2}{|c|}{ Obese } & \multicolumn{2}{|c|}{ Non obese } & \multirow{2}{*}{ P value } \\
\cline { 2 - 5 } & No. & Percentage & No. & Percentage & \multirow{2}{*}{0.248} \\
\hline Cases with lacerations & 4 & $5 \%$ & 2 & $2 \%$ & \multirow{2}{*}{$0.24 \%$} \\
\hline Total VD & 71 & $100 \%$ & 78 & $100 \%$ & \\
\hline
\end{tabular}

On comparing between obese and non-obese women in relation to incidence of lacerations, we found 4 cases with lacerations in obese group compared to 2 cases in non-obese group but not statistically significant $(\mathrm{P}$ value $>0.05)$. 
Table (9): Comparison between obese and non-obese of different studied groups in relation to 5-min. Apgar score.

\begin{tabular}{|c|c|c|c|}
\hline Variable & $\begin{array}{c}\text { Obese }(\mathbf{n}=\mathbf{1 0 0}) \text { Mean } \pm \\
\text { 1 Std. Deviation }\end{array}$ & $\begin{array}{c}\text { Non obese( } \mathbf{n}=\mathbf{1 0 0}) \\
\text { Mean } \pm \mathbf{1} \text { Std. } \\
\text { Deviation }\end{array}$ & P value \\
\hline 5-min. Apgar score & $8.90 \pm 0.745$ & $8.74 \pm 0.883$ & 0.168 \\
\hline
\end{tabular}

On comparing between 100 obese and 100 non-obese women in relation to $5 \mathrm{~min}$. Apgar score, we found no statistically significant difference between the obese and the non-obese groups ( $\mathrm{P}$ value $>0.05$ ).

Table (10): Comparison between obese and non-obese of different studied groups in relation to incidence of 5-min. Apgar score < 7

\begin{tabular}{|c|c|c|c|}
\hline Variable & Obese $(n=100)$ & $\begin{array}{l}\text { Non obese }(n= \\
100)\end{array}$ & $P$ value \\
\hline $\begin{array}{l}\text { No. of cases with } 5 \text {-min. } \\
\text { Apgar score }<7\end{array}$ & 4 & 1 & 0.258 \\
\hline
\end{tabular}

As regard low Apgar score at 5-min. (Apgar score < 7), we found slight increase in the incidence of low Apgar score at 5-min. in obese group compared to non-obese group but not statistically significant (P value $>0.05)$.

Table (11): Comparison between obese and non-obese of different studied groups in relation to neonatal birth weight.

\begin{tabular}{|c|c|c|c|}
\hline Variable & $\begin{array}{c}\text { Obese }(\mathbf{n}=\mathbf{1 0 0}) \text { Mean } \pm 1 \\
\text { Std. Deviation }\end{array}$ & $\begin{array}{c}\text { Non obese }(\mathbf{n}=100) \text { Mean } \\
\mathbf{1} \text { 1 Std. Deviation }\end{array}$ & P value \\
\hline $\begin{array}{c}\text { Neonatal birth weight (in } \\
\text { Kg.) }\end{array}$ & $3.289 \pm 375$ & $3.258 \pm 413$ & 0.580 \\
\hline
\end{tabular}

On comparing between 100 obese and 100 non-obese women in relation to neonatal birth weight, we found no statistically significant difference between the 2 groups ( $P$ value $>0.05$ ).

Table (12): Comparison between obese and non-obese of different studied groups in relation to incidence of fetal macrosomia.

\begin{tabular}{|c|c|c|c|}
\hline Variable & Obese $(\mathbf{n}=\mathbf{1 0 0})$ & Non obese $(\mathbf{n}=\mathbf{1 0 0})$ & P value \\
\hline $\begin{array}{c}\text { Percentage of cases with fetal } \\
\text { macrosomia. }\end{array}$ & 3 & 1 & 0.780 \\
\hline
\end{tabular}

On comparing between 100 obese and 100 non-obese women in relation to the percentage of cases of fetal macrosomia, we found 3 cases with fetal macrosmia in obese group compared to 1 case in non-obese group but not statistically significant (P value $>0.05)$.

In Brief we found that obesity is associated with increased incidence of failure of induction of labor ending in CS delivery, increased duration of induction of labor till vaginal deliveries, increased incidence of low 5 min. Apgar score and fetal macrosomia.

\section{DISCUSSION}

Obesity became a worldwide epidemic and the prevalence of overweight and obesity have substantially increased in the last decades especially in women ${ }^{(9)}$.

Maternal obesity poses a significant risk to maternal and fetal health during pregnancy. Many studies confirmed the findings that obesity is associated with significant complications including stillbirth, gestational diabetes, pregnancy-induced macrosomia, associated cephalopelvic disproportion, fetal distress and failed labour induction. The effect of obesity is higher in nulliparous than in parous women ${ }^{(10)}$. There is increased risk of maternal mortality. This risk is emphasized by the fact that more than $50 \%$ of all women who die from direct or indirect causes are either overweight or obese and more than $15 \%$ of all women who die from direct or indirect causes were morbidly obese ${ }^{(\mathbf{1 1})}$.

This study added to the increasing body, an evidence about the effect of BMI on success of induction of labor in past-date pregnancies.

As regard success of induction, our study revealed that a greater number of obese women had failed induction ending in CS delivery (no dilatation of cervix after 24 hours of vaginal prostaglandin) compared to their normal weight counterparts. This result goes hand in hand with 
Beckwith et al. ${ }^{(12)}$ who compared obese to nonobese women in an analysis stratified by induction method, prostaglandin versus mechanical. Misoprostol dosing was the same for obese and non-obese women. Pitocin was titrated to effect. Their primary outcome was failure to achieve active labor.

Secondary outcomes included overall cesarean delivery rate, doses of misoprostol used and need for protocol deviation. They found that obese women had a higher cesarean delivery rate with misoprostol $(35 \%$ versus $26 \%, \mathrm{p}=0.03)$ but not with mechanical ripening (31\% versus $29 \%$, $\mathrm{p}=0.69)$. Obesity was associated with a higher rate of failure to achieve active labor in women undergoing prostaglandin ripening with misoprostol (24 versus $15 \%, \mathrm{p}=0.01$ ) but not in women undergoing mechanical ripening (19 versus $15 \%, \mathrm{p}=0.55$ ).

Also this result comes in agreement with Ruhstaller et al. ${ }^{(13)}$ who found that obese women had an increased rate of failure of induction of labor, a rate that rises significantly with increasing body mass index. Ronzoni et al. ${ }^{(14)}$ reached to similar results when he came with a study in which 7,543 singleton term pregnancies undergoing IOL (cervical dilatation at admission, $\mathrm{CDA} \leq 3 \mathrm{~cm}$ ) were divided according to BMI: underweight $(\mathrm{n}=325)$; normal weight $(\mathrm{NW})$ $(n=4,633)$; overweight (OW) $(n=1,610)$; and obese $(n=975)$. Age, parity, macrosomia, gestational age (GA), gestational weight gain (GWG), cervical dilatation at admission, and IOL indications were considered. They found a higher rate of macrosomia (15.0 vs. $11.1 \% ; \mathrm{p}<0.0001)$, earlier induction (GA $39.7 \pm 1.3$ vs. $40.1 \pm 1.3$ weeks; $\mathrm{p}<0.0001)$ for maternal indications $(39.1$ vs. $21.1 \% ; \mathrm{p}<0.001)$, and lower cervical dilatation at admission $(\leq 1 \mathrm{~cm} ; 66.4$ vs. $61.4 \%$; $\mathrm{p}<0.005$ ) were observed in obese versus normal weight. The rate of weight gain above the recommended range was higher in obese (obese $70.6 \%$ vs. normal weight $43.9 \% ; \mathrm{p}<0.001)$, despite a significantly lower mean gestational weight gain compared to normal weight $(14 \pm 7.5$ vs. $16.5 \pm 5.6 \mathrm{~kg} ; \mathrm{p}<0.001)$.

Compared with normal weight, OW and obese demonstrated a significantly higher rCS (OW $31.1 \%$ and obese $36.9 \%$ vs. normal weight 24.7\%; $\mathrm{p}<0.001)$. BMI represented an independent factor affecting the rCS (vs. normal weight; OW odds ratio [OR] 1.4; confidence interval [CI] 1.2-1.7; $<<0.001$; obese OR 2.3; CI $1.9-2.7 \mathrm{p}<0.001)$.

Data obtained from Kobayashi and Lim (15) matched with the results revealed in the present study. They found that obese pregnant woman is at increased risks of induction of labour, caesarean section, post-partum haemorrhage, infection, longer hospital stay, macrosomia and higher perinatal morbidity and mortality. Labour was more likely to be prolonged and dysfunctional, leading to the requirements for higher doses of oxytocin and increased risks of operative deliveries and morbidity.

Doherty et al. (16) found similar adverse outcomes related to increasing maternal weight.

Regarding duration of induction of labor till vaginal deliveries, we found that obese women had a slight increase in the median of duration of induction of labor till vaginal deliveries compared with normal weight women. This comes in agreement with Lassiter et al. (17) who did retrospective cohort study over two years found 329 patients who were $>37$ weeks of gestational age and had a Bishop score $<5$ prior to beginning induction. Patients were divided into three categories based on their BMI: Group 1: BMI $\leq 30 \mathrm{~kg} / \mathrm{m}^{2}$, Group 2: BMI 30 to $39.9 \mathrm{~kg} / \mathrm{m}^{2}$ and Group 3: BMI $\geq 40 \mathrm{~kg} / \mathrm{m}^{2}$. They found that As BMI increases, obese patients undergoing induction with misoprostol had a longer time to delivery, required more doses of misoprostol, required a longer duration of oxytocin and had higher cesarean delivery rate. Pevzner et al. (18) found that patients undergoing induction with misoprostol had a longer time to delivery, required more doses of misoprostol and required a longer duration of oxytocin.

Regarding the incidence of perineal tear and lacerations, we found in our study that there were no statistically significant differences in the incidence of perineal tear and lacerations between obese and non-obese patients. This comes in agreement with Hollowell et al. (19) and Heslehurst et al. ${ }^{(20)}$ who did a systematic review study investigating the relationships between obesity and impact on obstetric care.

They found that there was no significant relationship with tears and lacerations and maternal obesity. It was not possible to metaanalyse underweight or overweight and tears. However, there was no apparent relationship with overweight and perineal trauma, whereas underweight was seen to have a significantly inverse relationship with perineal trauma in one study (OR 0.70, 95\% CI 0.49, 0.99), and another study identified no significant relationship. Also Cedergren (21) reported that anal sphincter lacerations were not over-represented in a group of 3386 morbidly obese women (BMI $\geq 40 \mathrm{~kg}$ / $\mathrm{m}^{2}$ ).

As regards the effect of obesity on the incidence of postpartum hemorrhage, we found 
slight increase in the incidence of postpartum hemorrhage in the obese group compared to the non-obese group (estimated blood loss $>500 \mathrm{ml}$ for vaginal delivery and $>1000 \mathrm{ml}$ in CS delivery). This comes in agreement with Deshmukh et al. ${ }^{(22)}$, who did a study in which BMI of 500 pregnant women booked before 12 weeks calculated and categorized as normal, overweight, obese and morbidly obese. Pregnant women with systemic disease and previous LSCS were excluded. Antepartum, intrapartum and neonatal variables were studied, and statistical analysis was carried out. They found that postpartum hemorrhage, pyrexia, prolonged hospital stay and lactational dysfunction were strongly associated with raised BMI.

Our Analysis of the neonatal outcomes from all deliveries revealed a trend towards increase in the incidence of fetal macrosomia in obese compared to non-obese group. Data obtained from Deshmukh et al. ${ }^{(23)}$ and Frederick et al. ${ }^{(24)}$ came hand in hand with our observations and showed that pre-pregnancy BMI was directly proportional to infant birth weight. The retrospective study of Stepan et al. ${ }^{(25)}$ showed that the rate of newborns weighting $>4 \mathrm{~kg}$, increased significantly with increasing BMI (P < 0.001). Also Abenhaim et al. (26) found that increasing BMI category was associated with a higher incidence of macrosomia.

As regards Apgar score at 5 minutes, there was slight increase in the incidence of low Apgar score in the obese group compared to nonobese group. This comes in agreement with $\mathbf{Z h u}$ et al. (27) who found that maternal overweight or obesity increased the risk for $5 \mathrm{~min}$. Apgar score $<7$.

\section{CONCLUSION}

Based on our observations we concluded that obesity is associated with increased incidence of failure of induction of labor ending in CS, increased duration of induction of labor till vaginal deliveries, increased incidence of low 5 min. Apgar score and fetal macrosomia.

\section{REFERENCES}

1. Osama H, Romesh K (2017): Obesity: Practice essentials

background.http://emedicine.medscape.com/article/123 702-overview\#a1

2. Gray C, Leveno K, Bloom S, Spong C, Dashe J, Hoffman B, Casey B, Sheffield J (2014): Parturition, Biomolecular and physiological process in William's Obstet, a textbook of obstetrics. Prentice Hall international Inc., pp: 187-226.
3. Arrowsmith S, Wray S, Quenby S (2011): Maternal obesity and labour complications following induction of labour in prolonged pregnancy. BJOG., 118 (5): 578588.

4. WHO: World Health Organization (2016): Obesity and overweight. Fact sheet. Available at: https://www.who.int/news-room/factsheets/detail/obesity-and-overweight.

5.

https://journals.lww.com/.../2015/.../Practice Bulletin No 156 Obesity in Pregnanc...

6. American College of Obstetricians and Gynecologists (2014): Management of Late-Term and Post-term Pregnancies. Practice bulletin No. 146. Obstet Gynecol., 124: 3990-6

6. Catalano P (2018): Weight loss in overweight and obese pregnant women $(\mathrm{OW} / \mathrm{OB})$ : what is the effect on fetal growth? Abstract No. 349. Am J Obstet Gynecol., 1: S155.

7. Petrella E, Facchinetti F, Bertarini V (2013): Occurrence of pregnancy complications in women with BMI > 25 submitted to a healthy lifestyle and eating habits program. Abstract No. 55. Am J Obstet Gynecol., 1: S33.

8. Bishop EH (1964): Pelvic scoring for elective induction. Obstetrics \& Gynecology, 24 (2): 266-8.

9. Flegal KM, Graubard BI, Williamson DF, Gail MH (2015): Excess deaths associated with underweight, overweight, and obesity. Journal of the American Medical association, 293 (15): 1861-1867.

10. Arendas K, Qiu Q, Gruslin A (2017): Obesity in pregnancy: pre-conceptional to postpartum consequences. J Obstet Gynaecol Can., 30 (6): 477-88.

11. https://www.oaa-

anaes.ac.uk/assets/_managed/.../Reports/20062008\% 20CEMD.pdf

12. Beckwith L, Magner K, Kritzer S, Warshak CR (2016): Prostaglandin versus mechanical dilation and the effect of maternal obesity on failure to achieve active labor: a cohort study. J Matern Fetal Neonatal Med., 25: 1-6.

13. Ruhstaller K1 (2015): Induction of labor in the obese patient. Semin Perinatol., 39 (6): 437-40.

14. Ronzoni S, Rosen H, Melamed N, Porat S, Farine D, Maxwell C (2015): Maternal Obesity Class as a Predictor of Induction Failure: A Practical Risk Assessment Tool. Am J. Perinatol., 32 (14): 1298-304.

15. Kobayashi N1, Lim BH (2015): Induction of labour and intrapartum care in obese women. Best Pract Res Clin Obstet Gynaecol., 29 (3): 394-405.

16. Doherty DA, Magann EF, Francis J, Morrison JC, Newnham JP (2016): Pre-pregnancy body mass index and pregnancy outcomes. Int $\mathbf{J}$ Gynaecol Obstet., 95 (3): $242-7$.

17. Lassiter JR, Holliday N, Lewis DF, Mulekar M, Abshire J, Brocato B (2016): Induction of labor with an unfavorable cervix. J Matern Fetal Neonatal Med., 29 (18): 3000-2. 
18. Pevzner L, Powers BL, Rayburn WF, Rumney P, Wing DA (2009): Effects of maternal obesity on duration and outcomes of prostaglandin cervical ripening and labor induction. Obstet Gynecol., 114 (6): 1315-21.

19. Hollowell J, Pillas D, Rowe R, Linsell L, Knight $M$, and Brocklehursta P, Jozwiak M, Bloemenkamp KW, Kelly AJ (2014): The impact of maternal obesity on intrapartum outcomes in otherwise low risk women: secondary analysis of the Birthplace national prospective cohort study. BJOG., 121 (3): 343355.

20. Heslehurst N, Simpson H, Ells LJ, Rankin J, Wilkison J, Lang $\mathbf{R}$ et al. (2014): The impact of maternal BMI status on pregnancy outcomes with immediate short-term obstetric resource implications: a meta-analysis. Obes Rev., 9: 635-83.

21. Cedergren MI (2014): Maternal morbid obesity and the risk of adverse pregnancy outcome. Obstet Gynecol, 103: 219-224.

22. Deshmukh VL, Jadhav M, Yelikar K (2015): Association between maternal obesity and offspring Apgar score or cord $\mathrm{pH}$ : a systematic review and meta-analysis. Sci Rep., 5: 18386.
23. Deshmukh VL, Jadhav M, Yelikar K (2016): Impact of HIGH BMI on Pregnancy: Maternal and Foetal Outcome. J Obstet Gynaecol India, 66 (1): 1927.

24. Frederick IO, Williams MA, Sales AE, Martin DP, Killien M (2016): Pre-pregnancy body mass index, gestational weight gain, and other maternal characteristics in relation to infant birth weight. Maternal and child health journal, 12: 557-567

25. Stepan H, Scheithauer S, Dornhöfer N, Krämer T, Faber R (2016): Obesity as an Obstetric Risk Factor: Does It Matter in a Perinatal Center? Obesity, 14 (5): $770-3$.

26. Abenhaim HA, Kinch RA, Morin L, Benjamin A, Usher R (2016): Effect of pre-pregnancy body mass index categories on obstetrical and neonatal outcomes. Arch Gynecol Obstet., 275 (1): 39-43.

27. Zhu T, Tang J, Zhao F, Qu Y, Mu D (2015): Association between maternal obesity and offspring Apgar score or cord pH: a systematic review and metaanalysis. Sci 18386. 